\title{
Reduced incidence of retinopathy of prematurity
}

\author{
E Rowlands, A C W Ionides, S Chinn, H Mackinnon, C C Davey
}

\begin{abstract}
Aim-To audit the prevalence of retinopathy of prematurity (ROP) in a level 2 status neonatal unit.

Methods-Data were collected prospectively over 9 years from September 1989 to September 1998. Preterm infants were examined according to the Royal College of Ophthalmologists' guidelines and retinopathy graded following the International Classification of ROP. ROP 3-5 was analysed using logistic regression in relation to time, and to gestational age and birth weight.

Results-383 babies were examined. Mean gestational age fell over the 9 year period $(p=0.051)$ as did mean birth weight $(p<0.001)$. There was a decrease in the number of infants with ROP grades 3-5 over the 9 years $(p=0.045$ and, when adjusted for gestational age and birth weight, the decrease in ROP 3-5 was significant $(\mathrm{p}=0.03)$.

Conclusions-This study found a significant reduction in the incidence of ROP during the 9 years of the study period, despite a decrease in mean gestational age of and birth weight. The reduced incidence of ROP is attributed to improvements in ventilation techniques and overall care of the neonate, in particular the use of prenatal steroids and surfactant.

(Br f Ophthalmol 2001;85:933-935)
\end{abstract}

Recent advances in neonatal care have improved the survival rates for premature infants ${ }^{1}$ and this has been accompanied by an increase in the incidence of retinopathy of prematurity (ROP) ${ }^{2-4}$ ROP is a leading cause of childhood blindness ${ }^{56}$ and accounts for up to $10 \%$ of childhood blindness in developed countries..$^{7-9}$ To analyse our experience of the changing incidence of ROP an audit was undertaken.

\section{Materials and methods}

Infants were examined on the neonatal unit (NNU) at the Whittington Hospital between September 1989 and September 1998. The NNU has 23 cots, receives 250 babies a year, and has level 2 status. The infants were examined according to the Royal College of Ophthalmologists' guidelines that were published in $1995 .{ }^{10}{ }^{11}$ Preterm infants were

Accepted for publication 22 February 2001

Table 1 Mean birth weight and gestational age of three groups

\begin{tabular}{lllllll}
\hline & $\begin{array}{l}\text { Number of } \\
\text { babies }\end{array}$ & $\begin{array}{l}\text { Mean birth } \\
\text { weight }(g)\end{array}$ & $S D$ & $\begin{array}{l}\text { Number of } \\
\text { babies }\end{array}$ & $\begin{array}{l}\text { Mean gestational } \\
\text { age (weeks) }\end{array}$ & $S D$ \\
\hline $1989-91$ & 115 & 1361.7 & 631.6 & 124 & 29.8 & 3.7 \\
$1992-4$ & 115 & 1207.4 & 472.0 & 118 & 29.2 & 3.0 \\
$1995-7$ & 134 & 1134.5 & 372.3 & 136 & 29.0 & 2.8 \\
Total & 364 & 1229.3 & 505.0 & 378 & 29.3 & 3.2 \\
\hline
\end{tabular}

referred by the neonatologists according to (1) birth weight equal to or less than $1500 \mathrm{~g}$, (2) post-menstrual age equal to or less than 31 weeks, and (3) paediatrician's concern-for example, prolonged exposure to oxygen. Pupils were dilated using phenylephrine $2.5 \%$ and cyclopentolate $0.5 \%$ eye drops instilled 1 hour and 30 minutes before examination. Indirect ophthalmoscopy was performed using a 30 dioptre lens. Neither a lid speculum nor scleral depressor were routinely used. The examinations were performed mainly on a weekly basis and continued until vascularisation had reached zone 3. Those with ROP were screened at intervals indicated by the severity of the disease.

Data were recorded prospectively and the presence of retinopathy was graded following the International Classification of ROP. ${ }^{12}{ }^{13}$ Co-existing medical problems were identified at the time of examination from the medical case notes.

\section{Results}

A total of 383 babies were screened during the 9 year study period. Gestational age had been recorded in 378 babies and birth weight had been recorded in 364 babies. The mean gestational age of all infants over the study period was 29.3 weeks (SD 3.2, range 23-41). The mean birth weight of all infants over the study period was $1229 \mathrm{~g}$ (507 g, 110-4190). For purposes of data analysis the infants were divided into three groups (groups 1, 2, and 3) of consecutive 3 year periods of birth, 198991, 1992-4, and 1995-7. Mean gestational ages in weeks of the groups were 29.8 (SD 3.7), 29.2 (3.0), and 29.0 (2.8) respectively. The decrease was of borderline statistical significance when considered as a trend over the three groups $(p=0.051)$. The mean birth weights of the three groups were $1361 \mathrm{~g}$ (SD $632 \mathrm{~g}), 1207 \mathrm{~g}(472 \mathrm{~g})$, and $1134 \mathrm{~g}$ (372 g) respectively (Table 1, Fig 1 and 2), there being strong evidence for a decreasing trend over the year groups $(\mathrm{p}<0.001)$.

Over the 9 year period, 10 babies had ROP grades 3-5; eight had stage 3, one had stage 4, and one had stage 5 (Table 2). When the trend over the three birth year groups was estimated the decrease in ROP of grades 3-5 did not quite reach statistical significance (logistic regression $\mathrm{p}=0.051)$. However, there was a lower incidence in the later two groups than the earlier (odds ratio 0.20, $\mathrm{p}=0.02$ ). Adjusting for gestational age and birth weight, the incidence of ROP 3-5 decreased significantly $(p=0.03)$. The odds ratio per $100 \mathrm{~g}$ increase in birth weight was $0.82(\mathrm{p}=0.14)$ and the odds ratio per 1 week increase in gestational age was $0.676(p=0.045)$. This indicates that gestational age was more closely linked to ROP 


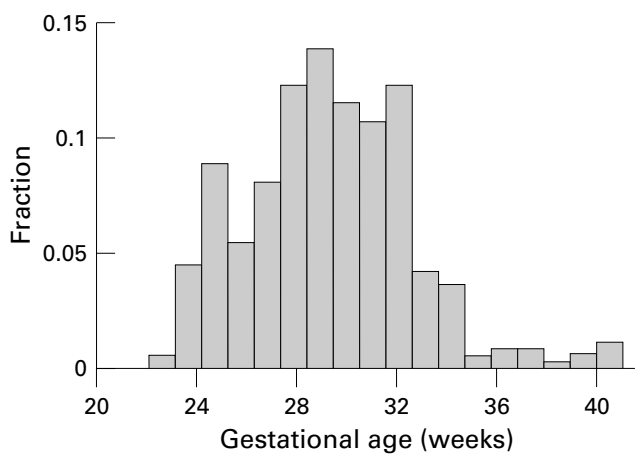

Figure 1 Distribution of gestational age.

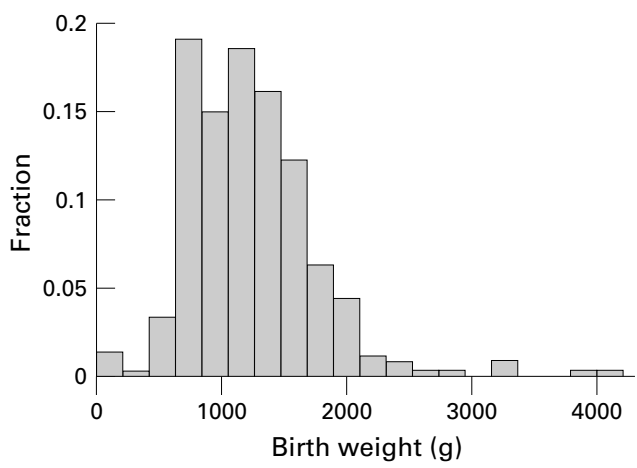

Figure 2 Distribution of birth weight.

Table 2 Grades of retinopathy of prematurity (ROP) in three groups

\begin{tabular}{llllllll}
\hline Grade ROP & 0 & 1 & 2 & 3 & 4 & 5 & Total \\
\hline Group 1 & 97 & 8 & 11 & 5 & 1 & 1 & 123 \\
Group 2 & 103 & 9 & 4 & 1 & 0 & 0 & 117 \\
Group 3 & 118 & 7 & 10 & 2 & 0 & 0 & 137 \\
Total & 318 & 24 & 25 & 8 & 1 & 1 & 377
\end{tabular}

3-5. The decrease of ROP 3-5 over the three groups was significant $(\mathrm{p}=0.04)$ when adjusted for gestational age alone and for birth weight alone $(\mathrm{p}=0.03)$. The decrease in ROP 3-5 was even more marked when groups 2 and 3 combined were compared with group 1 (odds ratio $0.20, p=0.02$ ). With adjustment for gestational age alone, the decrease in ROP 3-5 between group 1 and groups 2 and 3 combined was also greater (odds ratio $0.16, p=0.01$ ).

The mean age of infants with no ROP, ROP grade 1 and 2 was 29.4 weeks (SD 3.2). The mean age of infants with ROP 3-5 was 25.8 weeks (SD 1.6).

\section{Discussion}

There have been reports of improved survival rates for premature infants resulting in claims of an "epidemic" of ROP. ${ }^{7}$ In this study, despite a borderline decrease in the mean gestational age and a significant decrease in the mean birth weight, the incidence of ROP fell significantly. There was no reduction in the number of infants referred for ROP screening per year and there was a unified set of referral criteria and examination technique over the study period.

This study screened 383 infants over a 9 year period at an average rate of 43 infants per year. This is similar to data published from other units. Goble et al reviewed data from six neonatal units in Birmingham (UK), over a 6 year period and screened a total of 1611 babies $^{8}$ at a rate of 44.7 babies per neonatal unit per year. Severe ROP is seen predominantly in infants weighing less than $1000 \mathrm{~g},{ }^{14}{ }^{15}$ and the average birth weight of the screened population in the study by Goble et al was $1199 \mathrm{~g}$, similar to the average birth weights seen in this study $(1229 \mathrm{~g})$. The mean gestational age of the screened population in Goble's study was 29.1 weeks which again, is similar to the mean gestational age seen in this study which was 29.3 weeks.

The reduced incidence of grades ROP 1 and $2(13 \%)$ may relate to the examination technique. A lid speculum and scleral indentation were not routinely used and it is possible that some lower grades of ROP in the periphery were underdiagnosed. The examination technique would not, however, affect the diagnosis of ROP 3-5 and therefore not account for the decreased incidence of ROP $3-5$. It is recognised that many factors may contribute to differences in the incidence of ROP between centres, such as neonatal survival and ethnic mix. ${ }^{16}{ }^{17}$ The diagnoses by individual clinicians may also vary, ${ }^{18}$ but less so for severe disease. Although these factors may be relevant concerning studies comparing different centres, this study describes a trend within a single centre.

A decrease in the incidence of ROP has been reported from other centres. A Danish study found a decrease in the incidence of ROP for infants with birth weights between $1251 \mathrm{~g}$ and $1750 \mathrm{~g}$ although there was no decrease in incidence for the infants weighing less than 1251 g. ${ }^{19}{ }^{20}$ A multicentre UK study looking at neonates less than $1251 \mathrm{~g}$ found an increase in ROP in only one of five centres studied, suggesting that although there is increased survival of high risk neonates, this is not associated with a universal increase in severe ROP. ${ }^{21} \mathrm{~A}$ study from the United States found a decreased rate of progression from prethreshold to threshold ROP in infants studied between the years 1990-3 (7\%) compared to 1985-9 $(37 \%)$. Bullard et al found a decrease in the incidence of all levels of ROP across all birth weights at the Vanderbilt University Medical Centre in Tennessee. Their study compared infants born over a 12 month period between 1 July 1995 and 30 June 1996 with those born over a 23 month period between 1 January 1986 and 30 November 1987. They suggest that the decrease in both the incidence and severity of ROP may be attributed to the use of surfactant, continuous pulse oximetry, improved neonatal nutritional support, and the use of maternal antenatal steroids. ${ }^{22}$ However, Reynolds rejects the conclusions of Bullard et al stating that the single centre findings from the Vanderbilt University represent regression towards the mean and that this centre is now resembling the national mean. ${ }^{23}$ Furthermore, Reynolds goes on to state that controlled trials have shown no benefit from surfactant and that the multicentre LIGHT-ROP study showed no reduction in the incidence of ROP. ${ }^{24}$ 
There are many risk factors associated with the development of ROP. ${ }^{25-29}$ Apart from improvements in the general paediatric care of the infants, there were no other changes to the neonatal environment or the screened population during the study period that would alter the risks of developing ROP.

In conclusion, although this study is from a single centre and the number of patients (383) relatively small, it reflects a decreasing incidence and severity of ROP that is beginning to be found by other centres. This may reflect a regression towards the mean although if many centres are starting to have similar findings then this is unlikely. There is no single change in neonatal management to account for this and it may be that the improved general care of the neonate by the paediatricians (at this unit as well as nationally), combined with advances in prenatal management, have given rise to this trend.

1 Gong A, Anday E, Boros S, et al. One-year follow-up evaluation of 260 premature infants with respiratory distress ation of 260 premature infants with respiratory distress
syndrome and birth weights of 700 to 1350 grams syndrome and birth weights of 700 to 1350 grams
randomised to two rescue doses of synthetic surfactant or randomised to two rescue doses of synthetic surfactant or
air placebo. American Exosurf Neonatal Study Group I. $\mathcal{F}$ air placebo. American Ex

2 Valentine PH, Jackson JC, Kalina RE, et al. Increased survival of low birth weight infants: impact on the incidence of retinopathy of prematurity. Pediatrics $1989 ; 84$ $442-5$

3 Gibson DL, Sheps SB, Uh SH, et al. Retinopathy of prematurity-induced blindness: birth weight-specific survival and the new epidemic. Pediatrics 1990;86:405-12.

4 Schalij-Delfos NE, Cats BP. Retinopathy of prematurity: the continuing threat to vision in preterm infants. Acta Ophthalmol Scand 1997;75:72-5.

5 Nissenkorn I, Wijsenbeek Y, Cohen S, et al. Etiology of blindness in children in Israel in recent years. Acta XXV Concil Ophthalmol 1987;25:742-4.

6 Steinkuller PG, Du L, Gilbert C, et al. Childhood blindness. Steinkuller PG, Du L, Gilb
f AAPOS 1999;3:26-32.

7 Goggin M, O'KeefeM. Childhood blindness in the Republic of Ireland; a national survey. $\mathrm{Br} f \mathrm{f}$ Ophthalmo lic of Ireland;

8 Fleck BW, Dangata Y. Causes of visual handicap in the Royal Blind School, Edinburgh, 1991-2. Br f Ophthalmol 1994; 78:421.

9 Gibson DL, Sheps SB, Schechter MT, et al. Retinopathy of prematurity: a new epidemic? Pediatrics 1989;83:486-92.

10 Report of a Joint Working Party. Retinopathy of prematurity: guidelines for screening and treatment. London: Royal College of Ophthalmologists and British Association of Perinatal Medicine, 1995.

11 Goble RR, Jones HS, Fielder AR. Are we screening too many babies for retinopathy of prematurity? Eye 1997;11: 509-14

12 International Committee. An international classification of retinopathy of prematurity. Br 7 Ophthalmol 1984;68:6907.

13 The International Committee for the Classification of the Late Stages of Retinopathy of Prematurity. An International Classification of Retinopathy of Prematurity. II. The classification of retinal detachment. Arch Ophthalmol 1987; 105:906-12.

14 Moore AT. Screening for retinopathy of prematurity. (Editorial.) Eye 1992;6:233.

15 Fielder AR, Shaw DE, Robinson J, et al. Natural history of retinopathy of prematurity: a prospective study. Eye 1992;6:233-42.

$16 \mathrm{Ng}$ YK, Fielder AR, Shaw DE, et al. Epidemiology of retinopathy of prematurity. Lancet 1988;ii:1235-8.

17 Charles JB, Ganthier R, Appiah AP. Incidence and characteristics of retinopathy of prematurity in a lowincome inner-city population. Ophthalmology 1991;98:1417 .

18 Freedman SF, Kylstra JA, Hall JG, et al. Plus disease in retinopathy of prematurity: photographic evaluation by an expert panel. Invest Ophthalmol Vis Sci 1995;36(Suppl):18.

19 Fledelius HC. Retinopathy of prematurity in a Danish county: trends over the 12-year period 1982-93. Acta Ophthalmol Scand 1996;74:285-7.

20 Fledelius HC, Dahl H. Retinopathy of prematurity, a decrease in frequency and severity. Trends over 16 years in a Danish county. Acta Ophthalmol Scand 2000;78:359-66.

21 Vyas J, Field D, Draper ES, Woodruff G, et al. Severe retinopathy of prematurity and its association with different rates of survival in infants of less than $1251 \mathrm{~g}$ birth weight. Arch Dis Child Fetal Neonatal Ed 2000;82:F145-9.

22 Bullard SR, Donahue SP, Feman SS, et al. The decreasing incidence and severity of retinopathy of prematurity. $\mathscr{f}$ AAPOS 1999;3:46-52.

23 Reynolds JD. Incidence and severity of retinopathy of prematurity. f AAPOS 1999;3:321-2.

24 Reynolds JD, Hardy RJ, Kennedy KA, et al. Light reduction in retinopathy of prematurity (LIGHT-ROP) Cooperative group. Lack of efficacy of light reduction in preventing group. Lack of efficacy of light reduction in preventing 6.

25 Ben Sira I, Nissenkorn I, Kremer I. Retinopathy of prematurity. Surv Ophthalmol 1988;33:1-16.

26 Gumm TR, Easdoown J, Outerbridge EW, et al. Risk factors in retrolental fibroplasia. Pediatrics 1980;65:1096-100.

27 Schaffer DB, Palmer EA, Plotsky DF, et al. Prognostic factors in the natural course of retinopathy of prematurity. The Cryotherapy for Retinopathy of Prematurity Cooperative Group. Ophthalmology 1993;100:230-7.

28 Campbell PB, Bull MJ, Ellis FD, et al. Incidence of retinopathy in tertiary newborn intensive care unit. Arch Ophthalmol 1983;101:1686-8.

29 Broen DR, Biglan AW, Stretavsky MM, et al. Retinopathy of prematurity: the relationship with intraventricular haemorrhage and bronchopulmonary dysplasia. F Pediatr Ophthalmol Strabismus 1990;27:268-71. 